\title{
TRANSGENIC PETUNIA WITH ZRNASE II GENE AS A NOVEL MODEL SYSTEM FOR INVESTIGATION OF VIRUS RESISTANCE
}

\author{
Andrii Potrokhov ${ }^{1}$ \\ Olga Ovcharenko ${ }^{2}$
}

DOI: https://doi.org/10.30525/978-9934-26-050-6-3

Modern plant biology has a great demand of a broader range of available model systems except of Arabidopsis for various specialized purposes. Petunia is a plant with a number of characteristics making it attractive as a model system. These characteristics include a short generation time, an easy growth habit, an easy transformation protocol and an amenity for biochemical analysis because of its large leaves and flowers [1].

Petunia plants can be infected with a number of RNA containing viruses: Tobacco Mosaic Virus, Cucumber Mosaic Virus, Potato Virus Y. Infected with the viruses cultivars have decreased decorative characteristics and can form a virus reservoir for uninfected plants. Its susceptibility to a number of plant viruses and simple transformation protocols makes it a convenient model object for genetic engineering of plants tolerant to viruses. Biotechnology approaches allow the production of transgenic plants with increased resistance to viruses. The main transgenic strategies for virus resistance include: RNA interference, coat protein mediated resistance, replicase mediated resistance, RNA dependent RNA polymerase medited resistance, RNA satellites, antisense RNAs, ribosome-inactivating proteins (RIP), ribonucleases, enhancement of HR/SAR, hammerhead ribozyme, microRNAs, plantibodies [2].

Wounding-induced ribonuclease encoding cDNAs isolated from Zinnia elegans are predominantly induced in response to wounding. Isolated ZRNase II gene from Zinnia elegance encodes extracellular ribonuclease, which

\footnotetext{
${ }^{1}$ Institute of Cell Biology and Genetic Engineering, Ukraine

${ }^{2}$ Institute of Cell Biology and Genetic Engineering, Ukraine
} 
hydrolyze virus genomic RNA at some stages of their penetration into the plant cell [3]. Destruction of viral RNA by RNases retards the development of the symptoms, mitigate their severity or localize the infection in tobacco [4].

The aim of our research was the production transgenic petunia plants expressing ZRNase II gene, detection of RNase activity and further determination of virus resistance of obtained plants.

Methods: Agrobacterium-mediated genetic transformation of leaf discs from two petunia varieties (5P and $\mathrm{M} 1$ ) have been conducted with A. tumefaciens AGL0 strain harboring pbi-RNS vector. T-DNA of pbi-RNS vector included ZRNase II, S-like RNase gene of Zinnia elegans controlled by p35 S CaMV derived from the cauliflower mosaic virus (CaMV) and npt II, neomycin phosphotransferase gene, under control of nopaline synthase promoter (pNOS). Neomycin phosphotransferase gene was used as selective marker. Genetic vector for transformation was kindly provided by Professor A.V. Kochetov (Institute of Cytology and Genetics, Siberian Branch, Russian Academy of Sciences, Novosibirsk, Russia). Plants were regenerated and selected on medium with $100 \mathrm{mg} / \mathrm{l}$ kanamicyne. PCR was used to analyze the presence of target and selective genes in the kanamicyne resistant plants. RNase activity was determined by colorimetric method in the presence of orcinol [5].

Results. After Agrobacterium-mediated transformation putative transgenic plants have been obtained and were grown on the MS media supplemented with kanamycin-sulfate. 8 petunia lines of M1 and 10 lines of P5 with pbiRNS vector were selected. Shoots of selected petunia lines spontaneously rooted on plant growth regulator free selective medium. Putative transformants were PCR tested with specific primers to confirm the presence of heterologous npt II and ZRNase II genes. From each variety three independent most vigorously growing kanamycin-resistant lines were selected for PCR. All the selected lines possessed the amplificated fragment with primers to npt II and ZRNase II genes. Non-transgenic plants of both petunia cultivars were also analyzed to ensure the absence of the transgenes there. There was no amplification of the nesessary fragment with primers to these genes in control plants

Activity essay was performed to estimate the native RNase level in nontransgenic plants and to compare with the RNase activity in transgenic (fig.1). The RNase activity of all tested non-transformed cultivars was on the similar level. Transgenic plants have been found to have significantly $(\mathrm{P} \leq 0,05)$ higher levels of RNase activity compared to non-transgenic control. 


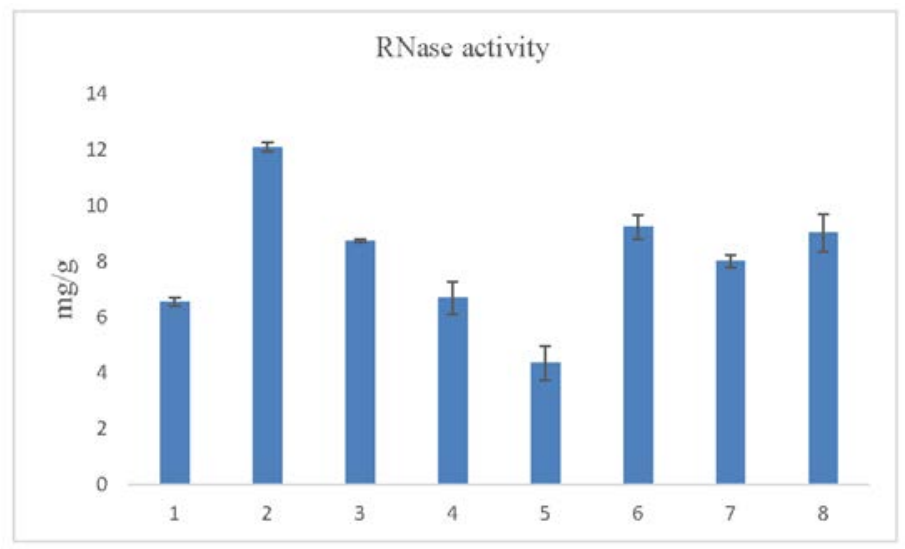

Figure 1. The RNase activity of extracts from petunia leaves, measured in mg of destroyed RNA per $\mathrm{g}$ of fresh weight

1, 5 -untransformed control M1 and 5P petunia plants, respectively; 2-4 -independent transformed lines of M1 petunia; 6-8 - independent transformed lines of 5P petunia

$\mathrm{T}_{0}$ plants were transferred to soil for further tests on virus resistance.

Conclusions. In our experiments we have obtained transgenic plants with ZRNase gene. The PCR analysis confirmed the ZRNase II gene integration into the petunia genome. RNase activity in transgenic lines exceeded that in non transgenic ones. Investigations of resistance to TMV of greenhouse grown plants are in progress.

\section{References:}

1. Vandenbussche M, Chambrier P, Rodrigues Bento S and Morel P (2016) Petunia, Your Next Supermodel? Front. Plant Sci. 7:72. doi: 10.3389/fpls.2016.00072

2. Galvez, L. C., Banerjee, J., Pinar, H., \& Mitra, A. (2014) Engineered plant virus resistance. Plant Science, 228: 11-25. doi:10.1016/j.plantsci.2014.07.006

3. Kochetov, A. \& Shumny, V. (2017) Transgenic plants as genetic models for studying functions of plant genes. Russian Journal of Genetics: Applied Research. 7, No 4: 421-427. https://doi.org/10.1134/S2079059717040050

4. Trifonova E., Sapotsky M., Komarova L., Scherban A., Shumny V. et al. (2007) Protection of transgenic tobacco plants expressing bovine pancreatic ribonuclease against tobacco mosaic virus. Plant cell reports, 26:1121-1126. doi: 10.1007/s10535011-0206-4.

5. Jain A., Jain R., Jain S. (2020) Estimation of RNA Using Orcinol Method. In: Basic Techniques in Biochemistry, Microbiology and Molecular Biology. Springer Protocols Handbooks. Humana, New York, NY. https://doi.org/10.1007/978-1-49399861-6_23 